\title{
Reprocessing of Single-Use Medical Devices in hospital environment: evolution and future perspectives
}

\author{
Fátima Sofia Costa ${ }^{\mathrm{a}}$, Maria Olívia Pereira ${ }^{\mathrm{b}}$, Carlos Esteves $^{\mathrm{c}}$, and Jorge Carvalho ${ }^{\mathrm{c}}$
}

\begin{abstract}
These days, in hospital environment, reprocessing of Single-Use medical Devices (SUDs) is a practice used more and more often. Reprocessing of SUDs, in-house or by outsourcing, is a way for hospitals to produce cost savings and less quantity of waste. This review focuses on the evolution of SUDs reprocessing, as well as on the legislation and regulation associated, and discusses the potential risks involved. Historical evolution unveils that reprocessing is unequal between developed and developing countries, being the United States and Canada the more reprocessors countries. The control of this service ensures the safety of this practice, as it happens in developed countries. It is expected that the market of reprocessed SUDs will grow, and more hospitals will begin to reprocess these devices.
\end{abstract}

\section{INTRODUCTION}

The Single-Use medical Devices (SUDs) have been intended to be used for one person only during only one medical procedure [1]. US Food and Drug Administration (FDA) strengthened that these devices were not intended to be reprocessed and used for another patient. On the other hand, according to FDA, reusable medical devices were defined as devices that the healthcare providers can reprocess and reuse for several patients [2][3].

According to by European Regulation of 2017, the reprocessing of medical devices is defined as the process performed on a used medical device to allow its reuse in safe conditions [1]. It includes several processes, namely:

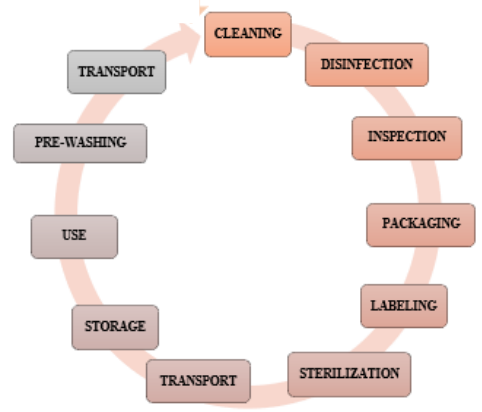

Figure 1. Reprocessing cycle of medical devices (adapted) [4].

a Centre of Biological Engineering, LIBRO - Laboratório de Investigação em Biofilmes Rosário Oliveira, University of Minho, Campus de Gualtar, 4710-057 Braga, Portugal; Centro Hospitalar do Médio Ave, E.P.E., 4780-371 Santo Tirso (e-mail: a74275@uminho.pt).

b Centre of Biological Engineering, LIBRO - Laboratório de Investigação em Biofilmes Rosário Oliveira, University of Minho, Campus de Gualtar, 4710-057 Braga, Portugal (e-mail: mopereira@deb.uminho.pt)

${ }^{c}$ Centro Hospitalar do Médio Ave, E.P.E., 4780-371 Santo Tirso (emails: carlos.esteves@chma.min-saude.pt, jorge.carvalho@chma.minsaude.pt). cleaning, disinfection, packaging, labeling, sterilization, transport and storage of the medical device, pre-washing after use, as well as functional and visual inspection (Fig. 1) [1][4]. These steps are necessary to ensure the traceability and maintain the sterility of the medical devices [2][5]. Each step is as important as the next one because a failure in any of the steps may lead to risks for the patients and the healthcare providers [6]. The SUDs can be reprocessed in health facilities or in third-party reprocessors [2][5]. This activity is very attractive, because by allowing a cost reduction for the health facilities, there may be an increase in investigation about innovative technologies, in new medical devices and in innovative therapies for the treatment of diseases [7].

So, this paper presents the state-of-the-art about reprocessing of SUDs in different countries and demonstrates that this practice is reliable in many countries. Thus, section II presents some important aspects of the reprocessing of SUDs, section III reports their historical evolution and finally, section IV gathers the main conclusions.

\section{REPROCESSING OF SUDS}

The health facilities began to reprocess SUDs due to reprocessing allows cost reduction because a reprocessed SUD can be used more than once. This situation contributes to the lower hospital waste production, which in addition reduces waste costs and the environmental impact [2].

Because it is a process with many associated risks, they have to be managed and estimated through a risk management plan, being also needed a quality management system with recommendations about the reprocessing [2][8]. The reprocessed SUDs are associated with a higher degree of risk when invasive medical procedures are used, i.e. critical procedures, and a lower degree of risk in noninvasive medical procedures, i.e. when the SUD is only in contact with the skin [8]. Furthermore, there are some complexities related to this practice, such as: the cleaning, difficulted by the shape of some devices, e.g. the cannulas, leading to infections [2][9]; and, the hard visual inspection of the critical surfaces of the devices in order to confirm the presence or absence of contaminants, having the necessity to use other inspection methods [2]. Also, there are some concerns, such as the modifications in the characteristics and in the performance of the SUD; the chemical products may degrade the material of the SUDs; whether the material does not withstand the process and may consequently fail mechanically; whether the sterilization does not eliminate bacterial endotoxins and the device has a high bacterial load after use, these endotoxins remain on the device even if the bacteria is dead [2][5]; the prion elimination is not achieved only for the decontamination and sterilization conventional methods, the more aggressive methods are the most 
appropriate, but are usually incompatible with the materials of the devices [5][8].

Therefore, it is important to have guidelines for the adequate reprocessing of the SUDs and to ensure patient safety. The health facilities must elaborate detailed procedures and protocols to reduce all risks or minimize them as much as possible. Thus, it is guaranteed that the reprocessing is performed correctly, standardized and in compliance with applicable regulations [2][7]. However, these specifications are related to the equipment and professionals' investment, which translates into high costs for hospitals [7]. So, the reprocessing outsourcing may be an advantage for the hospitals without appropriate conditions in sterilization service or qualified professionals [2]. In addition, the cost savings associated with reprocessing of SUDs might be higher than $90 \%$ when the reprocessing is performed inhouse and $50 \%$ when the reprocessing is performed by thirdparty reprocessors [7][10].

The responsibility of the manufacturers of SUDs ends when the device is no longer used in accordance with the conditions defined by the manufacturer in its technical documentation, instruction book and label [7]. For this reason, the reprocessed SUD is assumed as a new device, because it acquired a new feature, and the health organization, that allows the reprocessing of SUDs, has the liability to secure the safety and the functional performance of these devices [11][12].

\section{HISTORICAL EVOLUTION}

The evolution of reprocessing of SUDs started between 1970 s and 1980s in relation to advances in technology of synthetic materials, namely, plastics [7][13]. However, the harms in patients associated with the reprocessed SUDs began to appear, because there were no appropriate guidelines about the regulation of this process, leading to a decrease in the number of reprocessed devices [10]. On the other hand, the instruments with complex and smaller lumens and the more delicate manufacturing mechanisms hampered the appropriate cleaning or sterilization processes, leading to increase in the number of medical devices manufactured, labeled and marketed as SUDs [13]. In many countries, the decision to label a medical device as single-use or reusable is the liability of the manufacturer, which some devices are labeled as SUDs but really are reusable [14]. Ever since then, as the costs related to healthcare provision increased, many health facilities returned to the reprocessing of SUDs as a strategy for reducing costs [10].

In developed countries, the reprocessing of SUDs happens predominantly on medical devices of a higher economic value. In these countries, there are well defined control mechanisms and monitoring to reprocessing of SUDs. In contrast, in developing countries, the reprocessing is performed on more essential and scarcer medical devices. In these countries, it is essential that the reprocessing of these devices ends [14].

In 2017, the market of SUDs reprocessing was estimated to 1625.99 million USD [15], but nowadays, it is expected that in 2022 the international market of reprocessed medical devices grows to five billion USD, predominantly in developed countries [16].

Worldwide, International Organization for Standardization (ISO) elaborated some standards that must be complied in sterilization services of health institutions, mainly if they are interested in SUDs reprocessing, namely: ISO 9001, ISO 13485, ISO 14971, ISO 11607, ISO 15883 , ISO 17664, and ISO 10993 [1][6][11][18].

\section{A. United States of America (USA)}

In 1970, the reprocessing and reuse of SUDs began to appear in the USA when a recommendation against reprocessing and reuse of these devices was issued [16][18]. In 1985, this recommendation was rescinded and new guidelines about cleaning, disinfection, and sterilization of SUDs were issued. The reprocessors had to demonstrate to FDA that the features of SUDs were not altered and the device was safe and efficient for its intended purpose [19]. After 2000, a statement was issued with guidelines about reprocessing of SUDs. A study developed in 2002 claimed that approximately $25 \%$ of the hospitals reused SUDs and half of these hospitals hired third-party reprocessors, but a large majority of the hospitals reprocessed reusable medical devices in-house [19][20]. The hospitals and the third-party reprocessors must comply with the same requirements as the manufacturer of the original medical device [8].

In 2013, the cost savings from reprocessing of SUDs was estimated to approximately 20 thousand USD annually per operating room [16][21]. The American healthcare facilities disposed of more 1.8 billion $\mathrm{kg}$ of waste annually years ago, witch about $20-30 \%$ of this amount is from operating rooms [16][22].

A survey realized in 2017 demonstrated that $77 \%$ of respondents did not know that FDA allows the reprocessing and reuse of SUDs in hospitals, $65 \%$ and $84 \%$ of these respondents corresponded to physicians and patients respectively. However, it is expected that these numbers will decrease, mainly among physicians, because the reprocessing will grow in the coming years. Also, $59 \%$ of patients and $39 \%$ of physicians affirmed that they would be worried if SUDs were used in their surgeries. Regarding the informed consent, $92 \%$ of patients, $77 \%$ of healthcare providers and $68 \%$ of physicians thought that the hospitals should inform the patients about the use of reprocessed SUDs in their medical procedures, but this aspect is controversial because the hospitals will never agree with any procedure that would harm their patients. However, only $28 \%$ of participants would be worried about the possible increase of infection transmission associated with reprocessed SUDs [16].

\section{B. Canada}

The reprocessing of SUDs is currently accepted by Canadian law. There are guidelines to help health facilities that intend to reprocess SUDs [13][19]. The healthcare institutions should not reprocess SUDs, unless the institution has established quality systems about the existence of reuse and reprocessing commission, elaborating policies and procedures for each reprocessed SUD, validation of decontamination processes, and continuous monitoring of reprocessing procedures to guarantee quality [14].

Studies developed between 2006 and 2008 demonstrated that the most of Canadian hospitals did not reprocess SUDs, being that a small percentage of them never did it, but most of them already reprocessed them in the past [14][23]. The reasons related to this decision were mainly the legal responsibilities and the issues associated with patient safety. 
Also, it was possible to determine that most of hospitals reprocessors reprocessed SUDs in-house [25]. In 2014, the outsourcing of reprocessing increased considerably [25] and Health Canada (the department responsible for national public health [26]) began to regulate the SUDs reprocessing and issued conformity declarations [25][27]. In 2015, this department defined that the reprocessors facilities of SUDs had the same responsibilities as the original manufacturer. The legislation of this practice is applied to the reprocessed SUDs, both in the country and externally [25]. However, the health ministries of the Canadian provinces are responsible for some questions about reprocessing of SUDs [27].

\section{South America}

The reprocessed SUDs in Brazil, Colombia, Chile and Ecuador are usually more expensive devices, e.g. balloon and angiography catheters, arthroscopic rasps, pacemakers, and surgical knives. Particularly, the legislation in Chile prohibits the reprocessing of needles and medical devices used to intravenous therapies. However, hospitals may reprocess medical devices if a new device was open and not used in any patient, if the device is life supporting and there is no other choice to replace it, if the device can be cleaned adequately, and if a hemodialysis filter is used on the same patient [14].

\section{Oceania}

During the 1980s, a study exposed that about half of Australian hospitals reused SUDs, but in 2001 other study demonstrated that reprocessing of SUDs had decreased [14]. In 2003, some regulations about reprocessing of these devices were issued both for hospitals and for third-party reprocessors. It was referred that the healthcare facilities must state and prove the conformity against the same safety and functionality requirements that the manufacturers used for original devices [25][28]. However, over time, both Australia and USA detected a decrease in the number of hospitals that reprocessed in-house because of the legal responsibilities [25]. Australia and New Zealand have different requirements for reprocessing reusable medical devices and SUDs but little information is available [29]. In other countries there is no legislation about this practice.

\section{E. Asia}

In Asia, there are no regulations about reuse and reprocessing of SUDs, so the reuse of these devices is unregulated, unsafe and improper [27]. In 2005, a study demonstrated that approximately $80-90 \%$ of hospitals reused SUDs (the answer rate was about 30\%). These devices were not appropriate for being reused and reprocessed, e.g. needles and syringes for injections, leading to unsafe medical procedures [14][27]. In India, one person receives in average of about three to five injections annually and $60 \%-70 \%$ of these injections are delivered with unsterile and reused syringes and needles, inducing death of patients in India every day. This situation occurs similarly in Pakistan [14]. In Japan, the applicable requirements to SUDs require the appropriate labelling and prohibit their reuse and reprocessing [8]. However, the reuse of these devices continues to be a common practice. Also, in South Korea, at least until 2015, there was no legislation about the reprocessing of SUDs [27].

\section{F. Africa}

In Africa, the unsafe reuse of syringes and needles is also usual [14][27]. Some African countries do not have medical device manufacturers, third-party reprocessors or distribution companies to provide the medical devices needed to healthcare provision in hospitals. However, in 2010 some countries already possessed legislation about the reprocessing and reuse of medical devices [14]. Israel did not have any governmental control about this practice, besides that, many hospitals reprocessed and reused SUDs in 2015. In Saudi Arabia, there are general recommendations to regulate the medical devices [27]. South Africa has legislation about SUDs reprocessing, being this practice performed properly [30].

\section{G. European Union (EU)}

Depending on the legislation and regulations of each country, the reprocessing is performed in different forms in countries of EU [14]. In 1993, the European Parliament issued the Directive 93/42/EEC related to medical devices. This directive did not demand a distinction of the single-use and reusable medical devices and did not define a standard for reprocessing. Thus, the manufacturers could decide to label the medical devices as "single-use" or "reusable", according to their wishes [3][14]. In the following years, it was found that some reusable devices were altered to SUDs for the same use, therefore the hospitals began to reprocess SUDs [8]. The Directive 2007/47/EC was issued to clarify the definition of SUDs and standardize the labeling and the use instructions for these devices [14][30]. A study published in 2008 by European Commission demonstrated that $10 \%$ to $20 \%$ of devices labeled as SUDs were in fact reusable devices [7][14]. In 2010, the Scientific Committee on Emerging and Newly Identified Health Risks highlighted that not all SUDs are suitable for reprocessing, regarding the features, the complexity, and the intended purpose of the devices [18]. More recently, the Regulation (EU) 2017/745 mentions that the reprocessing of SUDs must be performed in an European country if this country allows it and complies with the requirements defined in this regulation. Moreover, it does not claim which classes of medical devices (class I, IIa, IIb and III) cannot be reprocessed [1].

In Germany, the legislation neither prohibits nor authorizes the reuse or reprocessing of SUDs, but there are regulations about this practice without distinguishing between SUDs and reusable devices [5][20]. Sweden allowed the reuse of SUDs, providing standards about patient safety and informed consent of patients on reprocessed SUDs [20]. In Belgium, if health facilities decide to reuse and reprocess SUDs, all healthcare providers are responsible for the quality and functionality of these devices and the manufacturer is no longer responsible [5]. Also, in Netherlands, Denmark, Slovakia, and Finland, there were recommendations on reprocessing of SUDs in 2010 [14]. France prohibits the reprocessing of SUDs since 2001 [5][32]. In Spain, Ireland, Italy, Czech Republic and Austria there were no recommendations on the reprocessing of SUDs [33]. In United Kingdom, a document with guidelines on the reprocessing of SUDs was issued in 2016, referring that reprocessing of class I medical devices must not be performed [34]. A new document about implications and 
consequences of SUDs reprocessing was emitted in 2018 [35].

In Portugal, there are recent and well-defined information about this service. An order was issued in 2013 about the establishment of rules and conditions for appropriate reprocessing of SUDs. It was noted that the reprocessing of implantable SUDs is forbidden [12]. In 2014, a deliberation was emitted to promote compliance with the previous order and provide requirements for SUDs reprocessing [11][36]. In May 2018, a new order was published to elaborate and determine the constitution of the workgroup to guarantee the reprocessing safety and quality [36]. Nowadays, most of the Portuguese hospitals hire third-party facilities for SUDs reprocessing, but the sterilization service of the "Centro Hospitalar do Médio Ave" has all the facilities and knowledge to in-house SUDs reprocessing and is certificated by appropriate standards.

\section{CONCLUSION}

Though SUDs reprocessing is not uniform worldwide, this is a promising practice that often results in cost savings for health facilities that may be used in new and innovative healthcare techniques and technologies. Moreover, it is expected that in countries with defined regulations on reprocessing, reprocessed SUDs do not endanger patient and healthcare providers. So, it is currently estimated that more and more hospitals will initiate the reprocessing over time. However, there is few current statistical data and recent information.

\section{REFERENCES}

[1] EUR-Lex, "Regulation (EU) 2017/745 of the European Parliament and of the Council of 5 April 2017 on medical devices, amending Directive 2001/83/EC, Regulation (EC) No 178/2002 and Regulation (EC) No 1223/2009 and repealing Council Directives 90/385/EEC and 93/42/EE," Off. J. Eur. Union, vol. 60, pp. 1-175, 2017.

[2] J. M. Mansur and JCI, "Reuse of Single-Use Devices: Understanding Risks and Strategies for Decision-Making for Health Care Organizations," pp. 1-12, 2017.

[3] EUR-Lex, "Council Directive 93/42/EEC of 14 June 1993 concerning medical devices," Off. J. Eur. Communities, vol. 36, pp. 1-43, 1993.

[4] G. McDonnell and D. Sheard, "Introduction," in A Practical Guide to Decontamination in Healthcare, First edit., Oxford, UK: WileyBlackwell, 2012, pp. 8-10.

[5] Eucomed, "Eucomed White Paper on the reuse of single use devices," pp. $1-58,2009$.

[6] World Health Organization, "Decontamination and Reprocessing of Medical Devices for Health-care Facilities," pp. 15-25-110, 2016.

[7] European Commission, "Synthesis Document - Outcome of the first public consultation on the reprocessing of medical devices," pp. 1-31, 2015.

[8] European Commission, "Report from the Commission to the European Parliament and the Council: Report on the issue of the reprocessing of medical devices in the European Union, in accordance with Article 12a of Directive 93/42/EEC," pp. 1-17, 2010.

[9] J. Azizi and R. J. Basile, "The Need to Verify The Cleaning Process," pp. 49-54, 2012.

[10]M. R. Tinkham, "Reprocessing of Single-Use Devices: Do the Benefits Outweigh the Potential Dangers?," Perioper. Nurs. Clin., vol. 5, no. 3, pp. 377-381, 2010.

[11]INFARMED, "Deliberação n. ${ }^{\circ}$ 939/2014, de 20 de março," Lisbon, 2014.

[12] Republic Ministry, "Despacho n. ${ }^{\circ}$ 7021/2013, de 24 de maio," Lisbon, 104, 2013.

[13]P. Jacobs, J. Polisena, D. Hailey, and S. Lafferty, "Economic Analysis of Reprocessing Single-Use Medical Devices: A Systematic Literature Review," Infect. Control Hosp. Epidemiol., vol. 29, no. 4, pp. 297-301, 2008.

[14]W. Popp et al., "What is the use? An international look at reuse of single-use medical devices," Int. J. Hyg. Environ. Health, vol. 213, no. 4, pp. 302-307, 2010.

[15] Mordor Intelligence, "Single-use Medical Device Reprocessing Market - Segmented by Type of Device (Class I and Class II) and Geography Growth, Trends, and Forecast (2018 - 2023),” 2018. [Online]. Available: https://www.mordorintelligence.com/industryreports/global-single-use-medical-device-reprocessing-market. [Accessed: 24-Nov-2018].

[16]P. Grantcharov, S. Ahmed, K. Wac, and H. Rivas, "Reprocessing and reuse of single-use medical devices: perceptions and concerns of relevant stakeholders toward current practices," Int J Evid Based Heal., vol. 16 , pp. $1-5,2018$

[17]ISO, "ISO 13485:2016 - Medical Devices - Quality management systems - Requirements for regulatory purposes," pp. 1-36, 2016.

[18] SCENIHR, "The Safety of Reprocessed Medical Devices Marketed for Single-Use," 2010.

[19]M. Parsons, "The dilemma over the reuse of 'single-use' medical devices. A risk manager's perspective.," Todays Surg Nurse, vol. 19, no. 3, pp. 31-2, 1997.

[20]D. Dunn, "Reprocessing Single-Use Devices - Regulatory Roles," AORN J., vol. 76, no. 1, pp. 98, 100-104, 106, 108-112, 114, 116, 118, $120,122,2002$.

[21]D. Carey, "Reprocessing and Reusing Single-Use Only Medical Devices: Safe Medical Practice or Risky Business?," J. Contemp. Heal. Law Policy, vol. 17, no. 2, pp. 657-685, 2001.

[22]S. Rodak, "Reprocessing Saves Up to \$20k Per OR Annually," Becker's ASC Review, 2013. [Online]. Available: https://www.beckersasc.com/asc-supply-chain-materialsmanagement/reprocessing-saves-up-to-20k-per-or-annually.html. [Accessed: 03-Nov-2018].

[23]J. DiConsiglio, "Reprocessing SUDs reduces waste, costs.," Mater. Manag. Health Care, vol. 17, no. 9, pp. 40-2, Sep. 2008.

[24]J. Polisena et al., "Reprocessing and Reuse of Single-Use Medical Devices: A National Survey of Canadian Acute-Care Hospitals," Infect. Control Hosp. Epidemiol., vol. 29, no. 5, pp. 437-439, 2008.

[25]Canadian Agency for Drugs and Technologies in Health, "Reprocessing of Single-Use Medical Devices: A 2015 Update," vol. 17, no. 48, pp. 1-11, 2015.

[26]"Health Canada - Government of Canada," 2018. [Online]. Available: https://www.canada.ca/en/health-canada.html. [Accessed: 16-Nov2018].

[27] AMDR, "AMDR Summary: International Regulation of 'Single-Use' Medical Device Reprocessing," Washington, 2015.

[28]Department of Health and Ageing, "Australian regulatory guidelines for medical devices (ARGMD)," 2011.

[29] Standards New Zealand and Standards Australia, "Australian/New Zealand Standard: Reprocessing of reusable medical devices in health service organizations (AS/NZS 4187:2014)," Wellington, 1, 2014.

[30]D. Vukelich, "South Africa Taking Steps to Advance Reprocessing," $A M D R$, 2018. [Online]. Available: https://amdr.org/2018/05/southafrican-firm-taking-steps-to-advance-reprocessing/. [Accessed: 28Nov-2018].

[31]EUR-Lex, "Directive 2007/47/EC of the European Parliament and of the Council of 5 September 2007 amending Council Directive 90/385/EEC on the approximation of the laws of the Member States relating to active implantable medical devices, Council Directive 93/42/EEC," Off. J. Eur. Union, vol. 50, pp. 21-55, 2007.

[32]A. Hernandez, "Reuso de dispositivos médicos para un solo uso," $E l$ Hospital, pp. 1-4, Aug-2013.

[33]I. Abreu, M. J. Abreu, and A. Coelho, "Reprocessing Single-Use Devices: Legislative issues in the EU," Eur. Med. Hyg., pp. 36-39, 2015.

[34]MHRA, "Single-use medical devices: UK guidance on remanufacturing," 2016.

[35]MHRA, "Single-use medical devices: implications and consequences of reuse," 2018.

[36] Republic Ministry and F. M. F. Araújo, "Despacho n. ${ }^{\circ}$ 4629/2018," Lisbon, 91, 2018. 